\title{
CARACTERIZAÇÃO GEOMORFOLÓGICA DA REGIÃO DE AURORA DO TOCANTINS, BRASIL
}

\section{GEOMORPHOLOGICAL CHARACTERIZATION OF AURORA DO TOCANTINS REGION, BRAZIL}

\author{
Fernando de Morais \\ Universidade Federal do Tocantins, Departamento de Geografia, Campus de Porto Nacional. \\ Rua 3 Quadral7 s|n, Jardim dos Ipês - CEP 77500-000 - Porto Nacional, TO - Brasil \\ E-mail:morais@uft.edu.br
}

\section{Informações sobre o Artigo}

Data de Recebimento:

$31 / 05 / 2012$

Data de Aprovação: 08/08/2013

\section{Palavras-chave:}

Geomofologia cárstica; cavernas; Tocantins.

\section{Keywords:}

Karst geomorphology; caves; Tocantins state.

\begin{abstract}
Resumo
Os estudos de geomorfologia do carste são contemporâneos ao próprio surgimento dessa ciência. A abordagem do revelo cárstico sob a ótica geomorfológica teve suas origens na região da atual Eslovênia, onde os trabalhos até hoje assumem o papel de vanguarda no desenvolvimento de métodos e procedimentos nesta área das ciências geográficas. No Brasil, os primeiros estudos apresentavam cunho mais paleontológico que geomorfológico, sendo mais desenvolvidos na porção centro-sul do país. O estado do Tocantins tem sido, mais recentemente, alvo de várias expedições exploratórias organizadas pela Sociedade Brasileira de Espeleologia e pela Universidade Federal do Tocantins. Assim, o presente estudo visa fazer uma explanação sobre os aspectos geomorfológicos gerais da área cárstica de Aurora do Tocantins, que apresenta o maior potencial para a ocorrência de cavernas no estado. Para tal, foram elaborados mapas temáticos sobre os aspectos fisiográficos da área além de terem sido realizados trabalhos de campo para a exploração e caracterização das maiores cavernas da área estudada. Os resultados apontaram que a maioria das cavidades que estão em franco processo de crecimento se desenvolveu sobre rochas calcárias do Grupo Bambuí. Estas feições estão em áreas dominadas por agricultura e pastagens, sendo que algumas delas utilizadas para a disposição de resíduos sólidos, a exemplo das dolinas e fendas calcárias.
\end{abstract}

\begin{abstract}
The studies of karst geomorphology are as contemporary as the appearance of this science. The approach to the karst landscape had its origins in the region of present day Slovenia, where the research started assume, until nowadays, the vanguard role in the development of methods and procedures in this area of the Earth Sciences. In Brazil, the first studies showed more paleontological discoveries than geomorphological ones, developing more in the centralsouthern portion of the country. More recently, the Tocantins State has been the main target of a variety of exploratory expeditions organized by the Brazilian Speleological Society and the Federal University of Tocantins. Thus, this study aims at discussing the general geomorphological aspects of the karst area located in Aurora do Tocantins which presents the biggest potential of cave occurrence in the state. For this reason, thematic maps focusing on fisiogeographic aspects of the area were developed together with field works for the exploration and characterization of the biggest caves. The results showed that the majority of caves developed in limestone of the Bambui Group are located in areas dominated by agriculture and pastures and some features such as dolines and limestone cracks are used as waste disposal.
\end{abstract}




\section{Introdução}

A maioria dos textos sobre a história da geomorfologia apontam W. M. Davis e W. Penck como os grandes nomes responsáveis pelo lançamento das bases teóricas desta ciência. Desde o final do século XIX muitas formas de abordagem, e algumas rupturas epistemológicas, têm contribuído para a especialização da geomorfologia em ramos como a geomorfologia fluvial, costeira, urbana etc. Dentre estes ramos, a geomorfologia do carste tem recebido a atenção de parte da comunidade científica pelo fato de tratar do relevo de aproximadamente $17 \%$ da superfície terrestre, onde ocorre o predomínio de rochas carbonáticas, principal, mas não o único, tipo de rocha propício à gênese de formas de relevo cárstico. Segundo Ford e Williams (2007), cerca de 25\% da população mundial vivem em áreas em que a principal fonte de abastecimento, tanto domiciliar quanto industrial, constitui-se de aquíferos cársticos. Karmann (1994) estima que aproximadamente $5-7 \%$ do território brasileiro são constituído por relevo cárstico.

No Brasil, várias áreas de relevo cárstico têm sido estudadas desde que os colonizadores aqui chegaram. Dentre vários trabalhos, destacam-se os realizados por naturalistas estrangeiros como Peter Wilhelm Lund (séc. XIX) e Ricardo Krone (séc. XX), nos estados de Minas Gerais e São Paulo, respectivamente. A partir da terceira década do século $\mathrm{XX}$, com a fundação da Sociedade Excursionista e Espeleológica (SEE) em Ouro Preto, Minas Gerais, os estudos do relevo cárstico começaram a ser realizados com maior frequência.

Karmann e Sanchéz (1979), baseados nos levantamentos geológicos do projeto RadamBrasil além de outras fontes, apresentaram a distribuição das rochas carbonáticas e províncias espeleológicas do Brasil. Quanto ao detalhamento da Província Espeleológica do Bambuí, os autores dividiram-na em cinco distritos espeleológicos (Distrito de São Domingos, Distrito de Brasília, Distrito do Alto e Médio São Francisco, Distrito de Irecê e Distrito do Alto Paraguaçu ou Piranhas) e apontaram a região do extremo sudeste do estado do Tocantins, com destaque para os municípios de Dianópolis e Aurora do Tocantins, como sendo uma área com grande potencial para a ocorrência de cavernas.

Desde as primeiras expedições organizadas pela Sociedade Brasileira de Espeleologia para a região de Aurora do Tocantins, várias pesquisas com a participação de professores e alunos de graduação e pós-graduação de várias universidades brasileiras começaram a dar um caráter mais científico ao entendimento da evolução do carste desta porção do Tocantins. Assim, o presente estudo busca fazer uma caracterização geral dos aspectos geomorfológicos da área cárstica de Aurora do Tocantins, que possuía mais de uma centena de cavernas descobertas e cadastradas até maio de 2013. Tal caracterização poderá dar suporte a futuros trabalhos de planejamento e gestão ambiental do carste da região.

\section{Área de estudo}

A área cárstica de Aurora do Tocantins está situada na porção sudeste do estado do Tocantins, na região norte do Brasil (Figura 1). O retâgulo envolvente definido para os trabalhos de prospecção espeleológica e caracterização geomorfológica compreende uma área de $6099,58 \mathrm{~km}^{2}$, entre os paralelos $12^{\circ} 10^{\prime} 00^{\prime}$ 'S e $13^{\circ} 05^{\prime} 00^{\prime}$ 'S e os meridianos $46^{\circ} 10^{\prime} 00^{\prime \prime} \mathrm{W}$ e $46^{\circ} 50$ '00' $\mathrm{W}$, englobando as sedes dos municípios de Taguatinga, Aurora do Tocantins, Lavandeiras, Combinado, Novo Alegre e Campos Belos. Esta área foi definida de forma a abranger os grandes maciços calcários e as cavidades que já tinham sua localização conhecida antes desta pesquisa.

Segundo Karmann e Sánchez (1979), esta área está situada no Distrito Espeleológico de São Domingos, sendo caracterizada por extensos afloramentos calcários intensamente lapiezados com a maior concentração de cavernas nas proximidades das cidades de Campos Belos e Aurora do Tocantins. Os mesmos autores destacam a grande quantidade de dolinas encontradas neste distrito espeleológico.
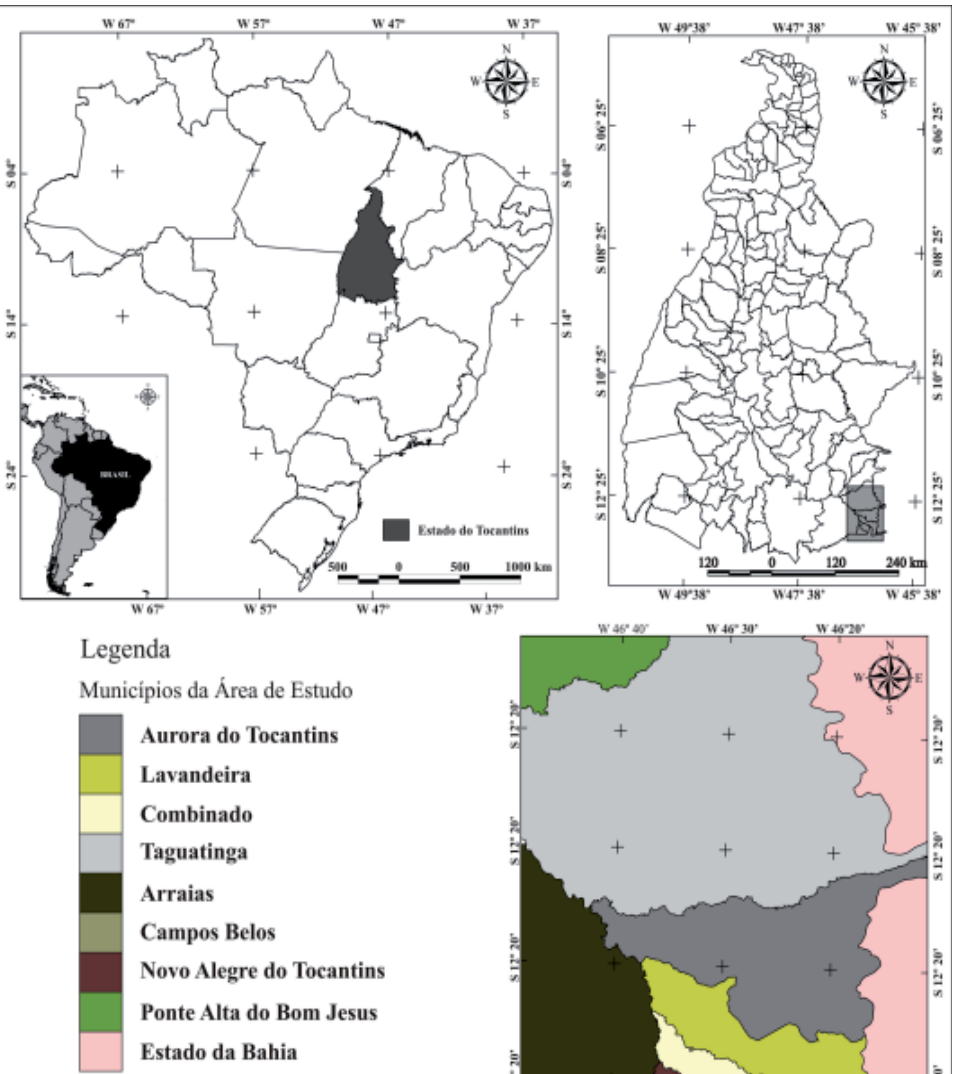

Fonte: INPE - 2010

Projeçăo Polyconic

Datum: SIRGAS 2000

Ediçâo: Gilney Cardoso Pereiri



Figura 1 - Mapa localização da área de estudo. 
O clima da região é considerado sub-úmido seco com moderada deficiência hídrica no inverno. As precipitações médias anuais oscilam entre 1.400 e $1.600 \mathrm{~mm}$ com temperatura média anual variando entre 25 e $27^{\circ} \mathrm{C}$ (SEPLAN, 2008).

No que diz respeito à geologia, a área de estudo situase nos domínios da Bacia Sedimentar Sanfranciscana, com ocorrência das seguintes unidades geológicas da base para o topo: Complexo Almas-Cavalcante (Embasamento Cristalino), Grupo Bambuí, Grupo Urucuia, Grupo Areado e Depósitos Aluvionares Recentes (Figura 2), embora existam divergências sobre a hierarquia estatigráfica regional (CAMPOS; DARDENNE, 1994; SGARBI, 1991 e 2000).

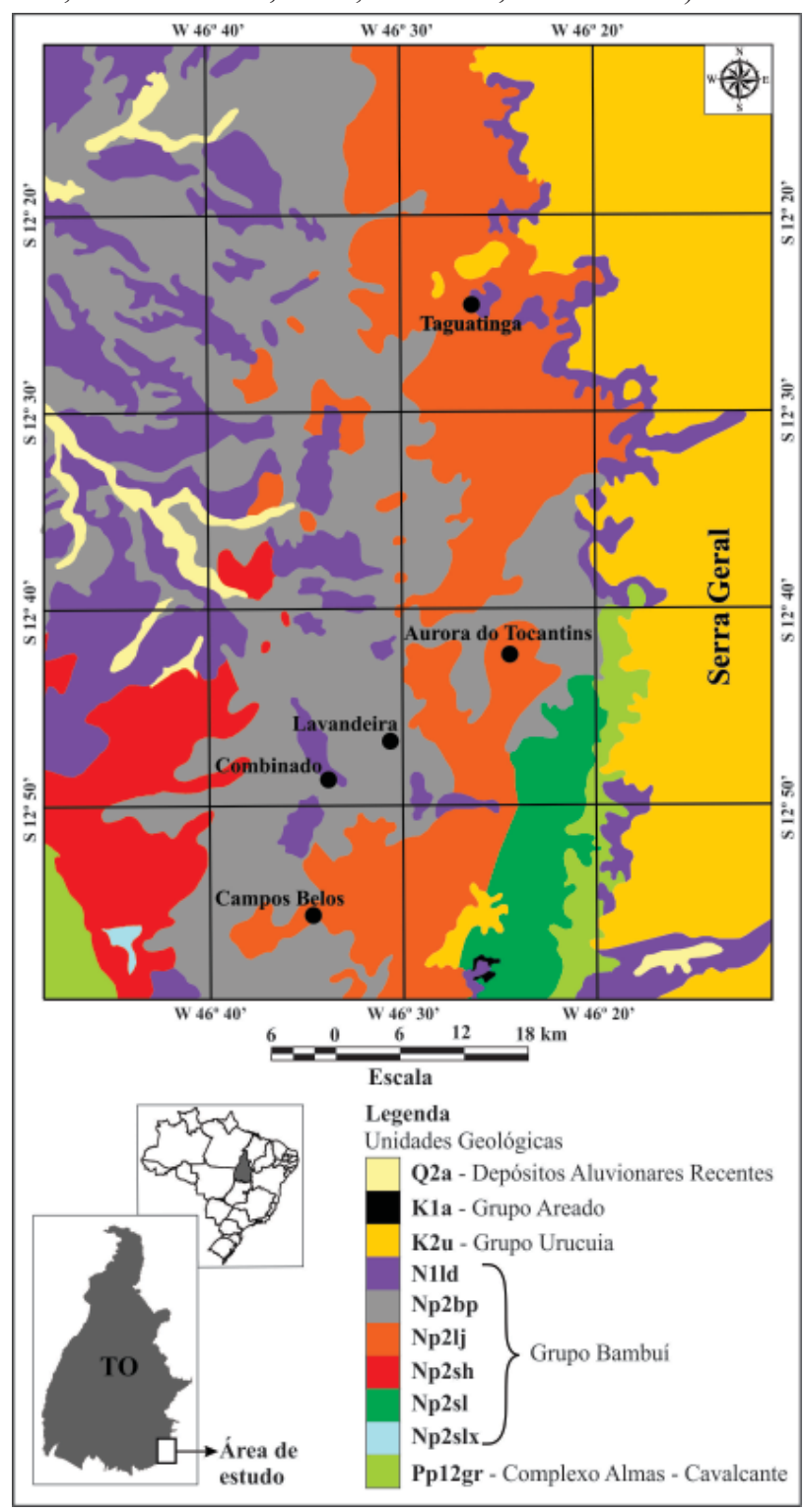

Figura 2 - Mapa geológico da área de estudo (simplificado de SOUZA et al., 2004).
O Complexo Almas-Cavalcante constitui o embasamento cristalino na área de estudo e pode ser notado principalmente nas proximidades da Serra Geral. De idade cretácea, o Grupo Urucuia é composto pelas formações Posse e Araras, sendo constituído por arenitos, com níveis de pelitos, arenitos conglomeráticos e ocorrências de conglomerados (CAMPOS; DARDENNE, 1997). Na área cárstica de Aurora do Tocantins, este grupo geológico é mais notável na porção leste, nos afloramentos que compõem o Planalto Divisor São Francisco - Tocantins, podendo também ser notado em vários outros pontos da região.

De acordo com Souza et al. (2004), o Grupo Bambuí, de idade neoproterozóica, é composto por calcarenitos, dolomitos, ritmitos, margas, argilitos, siltitos, arcóses e calcários, que compõem o Sub-grupo Paraopeba, que se distribui por grande parte da área de estudo e comporta a maioria das feições cársticas.

A geomofologia da área estudada apresenta planaltos e depressões que passaram por processos de pediplanação. O planalto divisor das bacias hidrográficas dos rios São Francisco e Tocantins (Serra Geral) domina a porção leste da área, onde o Chapadão Central e os Patamares do Chapadão são as unidades geomorfológicas que mais se destacam na paisagem. De acordo com Brasil (1982), o Chapadão Central guarda em seus topos feições herdadas de uma superfície de aplainamento estruturada sobre os sedimentos da Bacia Sanfraciscana, apresentando vales fluviais assentados no contado do Grupo Urucuia com o Grupo Bambuí. Os processos geomorfológicos atuantes nesta porção da área de estudo são os mesmos conhecidamente responsáveis pela evolução da paisagem de outras regiões de relevo tabuliformes e cuestiformes, com destaque para a ocorrência de remanejamento constante de areia das partes mais elevadas para as mais deprimidas, onde estão instaladas as veredas. Os Patamares do Chapadão caracterizam-se pelos topos planos com interflúvios largos e pouco dissecados por ravinamentos. As formas de dissolução instaladas nos calcários do Grupo Bambuí são as feições que melhor caracterizam a natureza cárstica da área (BRASIL, 1982).

No tocante às partes rebaixadas da região, destacam-se a Depressão do São Francisco - Rio de Contas e a Depressão do Tocantins, sendo esta última mais dominante na área de estudo, onde o Pediplano do Tocantins se apresenta de forma descontínua por uma grande área que engloba toda a bacia do rio Palma (BRASIL, 1982). Na sua porção ocidental, destaca-se a ocorrência de inselbergs, enquanto a parte oriental deste pediplano, que se apresenta como uma superfície de aplainamento retocada inumada, e está conectada às escarpas (cornijas estruturais) do Chapadão Central, citado anteriormente. 
As formas de dissolução estão distribuídas descontinuamente pelas áreas dominadas pelo planalto chamado Patamares do Chapadão e pela depressão denominada Vão do Paranã. Essa depressão está situada entre o Planalto Divisor São Francisco - Tocantins e o Planalto Central Goiano. Segundo Brasil (1982), os calcários desta área se distribuem em forma de cristas orientadas na direção N-S. Podem-se notar planos encouraçados nos interflúvios, onde as partes mais baixas da depressão apresentam cobertura coluvial pouco espessa. Enquanto os Patamares do Chapadão apresentam carste coberto, carste em exumação e carste descoberto, as formas de dissolução do Vão do Paranã constituem relevo cárstico descoberto e em processo de exumação.

As formas cobertas e em processo de exumação ocorrem principalmente na porção centro-leste da área, tornando-se menos visíveis à medida que se aproximam da Serra Geral. Já o carste descoberto, que é caracterizado por formas como lapiás, dolinas, uvalas, poljés e cavernas, dentre outras feições, é mais visível na porção central, com grandes afloramentos distribuídos no sentido sul-norte, além de ocorrem também na porção sudoeste da área de estudo. Ocorrem ainda, de maneira pontual, planícies de acumulações recentes. Segundo Brasil (1982), essas áreas correspondem aos pontos de acumulação fluvial, caracterizados como várzeas, que são propícias a inundações periódicas em função dos regimes fluviais das drenagens da bacia hidrográfica a que pertencem.

\section{Materiais e métodos}

Os trabalhos na área de geomorfologia cárstica podemse valer de uma gama variada de procedimentos metodológicos, selecionados consoante os objetivos almejados. Assim, trabalhos de cunho mais hidrológico tendem a adotar procedimentos típicos da Hidrologia e Hidrogeologia Clássica, com algumas adaptações, de forma a atender às peculiaridades do carste. Trabalhos que primam pela abordagem acerca da evolução cíclica do relevo cárstico tendem à adoção de procedimentos usuias na geomorfologia de uma forma geral.

Para o desenvolvimento deste estudo, buscou-se fazer uma junção dos procedimentos típicos da geomofologia cárstica, incluíndo a consulta aos trabalhos mais antigos sobre os aspectos fisiográficos da área de estudo como os relatos de viagens (GARDNER, 1975; AIRES DE CASAL, 1976; POHL, 1976 e PEREIRA, 1942 e 1943) além de consultas à população local sobre a ocorrência de cavidades na porção sudeste do estado do Tocantins. Após esse levantamento e consultas ao Cadastro Nacional de Cavidades, disponível no endereço eletrônico da Sociedade Brasileira de Espeleologia - SBE, foi então delimitada a área de estudo.

Com o auxílio de imagens do Satélite Landsat 5 sensor TM (Thematic Mapper) com resolução de 30m, que são disponibilizadas gratuitamente pelo Instituto Nacional de Pesquisas Espaciais - INPE, foram elaborados mapas de Uso e Ocupação do solo da área (Figura 8). Tais imagens auxiliaram ainda na vetorização da rede de drenagem, que se deu inicialmente com a utilização das cartas topográficas Arraias (SD.23-V-A-VI), Aurora do Norte (SD.23-V-B-IV), Taipas (SD.23-V-A-III) e Taguatinga (SD.23-V-B-I), todas elaboradas pela Diretoria de Serviço Geográfico do Ministério do Exército na escala de 1:100.000. Com os dados do projeto TOPODATA (VALERIANO, 2008), foram elaborados mapas de hipsometria, declividade e sombreamento do relevo (Figura 3). Para o georreferenciamento e adequação de projeção e datum, além de toda a confeção de mapas temáticos, utilizou-se os softwares Global Mapper 12.01, licenciado para o LGA (Laboratório de Análises Geoambientais da Universidade Federal do Tocantins) e SPRING 5.1.7, distribuído gratuitamente pelo INPE.

Com a utilização de imagens do satélite Landsat 5 sensor TM (Thematic Mapper), com resolução espacial de 30 $\mathrm{m}$ referentes ao mês de abril do ano de 2010, foi elaborado um mapa de uso e ocupação da área de estudo. Para tal, foi realizada a segmentação da imagem em cinco classes temáticas (agricultura/pastagens, vegetação natural, afloramentos rochosos, solo exposto e área urbana) a partir de uma composição colorida das bandas 5(R) 4(G) 3(B).

Após a confecção dos mapas base, foram realizados trabalhos de prospecção e caracterização das maiores cavernas presentes na área. Para tal, adotaram-se os procedimentos propostos por Dias (2003), que elaborou uma ficha que auxilia no detalhamento das características espeleométricas (medidas dos condutos e salões, altura do maciço, dentre outras), condições hidrológicas e hidrogeológicas, aspectos bioespeleológicos, paleontológicos, arqueológicos e condições de conservação da cavidade e seu entorno. Além das anotações sobre as feições endocársticas, foram feitas observações gerais das principais feições exocársticas, como recomendam Carvalho Júnior et al. (2008), visando o entendimento do sistema cárstico em sua totalidade.

\section{Exocarste}

A partir do mapa de relevo sombreado (Figura 3), podese observar que as partes mais elevadas do relevo dominam a porção leste da área de estudo, onde ocorre a recarga das drenagens responsáveis pela manutenção do fluxo de base na bacia do rio Palma, principal manancial hídrico da região sudeste do estado do Tocantins. Levando-se em consideração a área de litologia não carbonática para o entendimento do sistema em sua totalidade, pode-se constatar que as formas típicas do carste não estão presentes na porção da área denominada Serra Geral, dominada por arenitos da Formação Urucuia e com altitudes variando de 800 a $1.100 \mathrm{~m}$. 
Na mesma figura ainda é possível observar que o relevo mostra maior rugosidade na porção central da área, onde os carbonatos do Grupo Bambuí estão distribuídos no sentido sul-norte. Nesta porção, as altitudes variam entre 400 e $600 \mathrm{~m}$, enquanto as altitudes inferiores a 400m dominam a porção noroeste da área.

No tocante à declividade, nas escarpas tabuliformes da Serra Geral, pode-se constatar valores superiores a 30\%. Tal valor pode ser constatado ainda em algumas localidades nas porções sudoeste e central da área, onde ocorrem grandes afloramentos areníticos. Entretanto, a maioria dos afloramentos carbonáticos estão associados às declividades que variam entre 5 e $20 \%$, também na porção central da área.

Além de observações do relevo na sua escala mais regional, $1^{\circ}$ ao $3^{\circ}$ taxons do relevo (ROSS, 1992), o presente estudo buscou caracterizar mais detalhadamente o relevo da Área Cárstica de Aurora do Tocantins. Assim, foram feitos caminhamentos e incursões aos pontos de maior interesse geomorfológico da área em estudo, enfatizando as formas superficiais mais típicas desse tipo de relevo, como os lapiás (karren), as dolinas, os poljes e os maciços calcários.

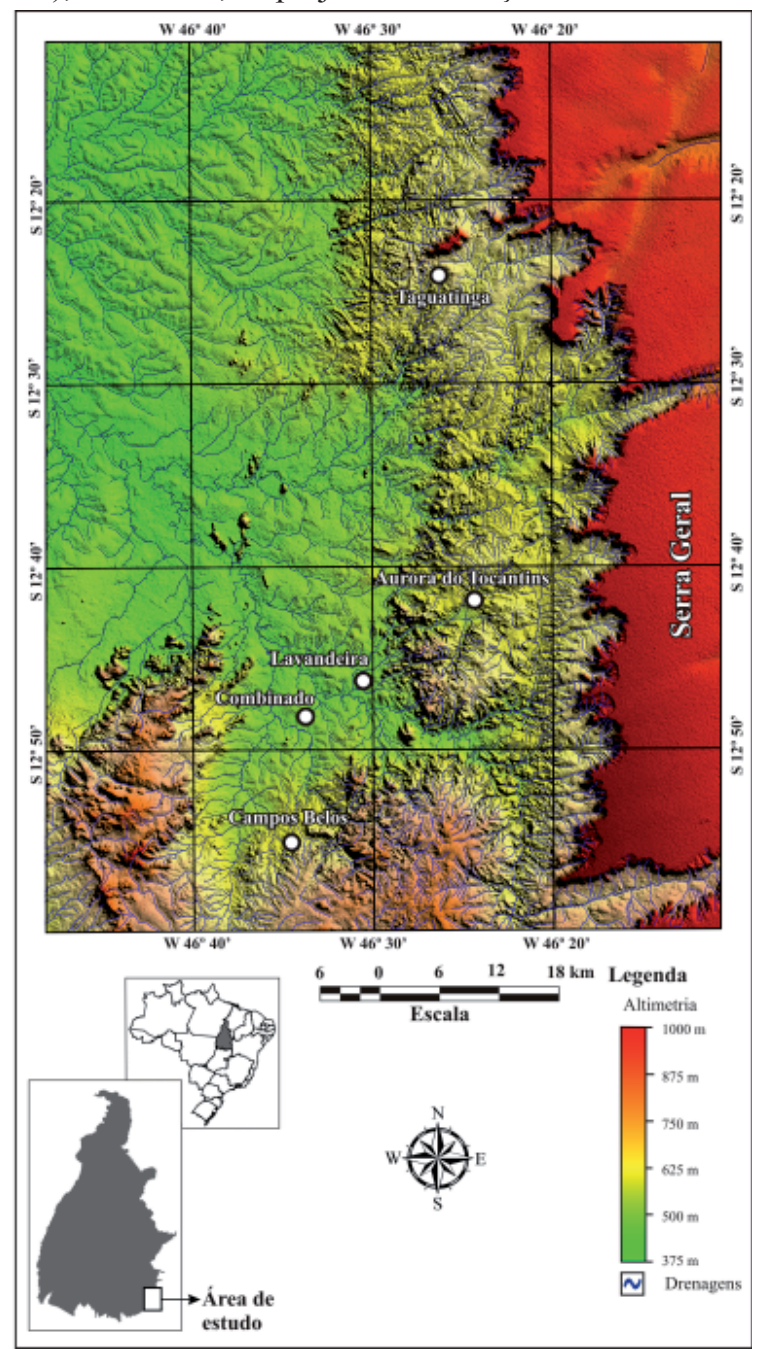

Figura 3-Mapa do relevo sombreado da área de estudo.
Os lapiás são feições de dissolução quase sempre de pequenas dimensões, que podem se desenvolver no exocarste, epicarste e endocarste (FORD; WILLIAMS, 2007). Uma classificação detalhada dessas feições foi elaborada por Bögli (1980), que definiu três grandes grupos de lapiás baseado em suas características genéticas (free karren, half free e covered karren).

$\mathrm{Na}$ área cárstica de Aurora do Tocantins ocorrem lapiás das mais diversas naturezas, com destaque para os lapiás verticais (rillenkarren) e os lapiás horizontais (Schichtenkarren), além de lapiás em pináculos (Spitzenkarren), em menor quantidade. Segundo Ford e Williams (2007), essas feições podem apresentar formas circulares, lineares e polimorfas, dependendo do controle genético, que pode ser hidrodinâmico ou condicionado por fraturas na rocha.

Os poljes (Figura 4) podem ser entendidos como depressões de base plana com planícies de dissolução em seu interior (FORD; WILLIAMS, 2007). Palmer (2007, p. 412) ressalta que tais planícies de dissolução geralmente constituem o nível de base local e podem ser comparadas às planícies de inundações dos vales fluviais maduros.

$\mathrm{Na}$ área estudada, três poljes chamam a atenção, um onde se situa o núcleo urbano de Aurora do Tocantins, outro situado a aproximadamente $7 \mathrm{~km}$ da cidade de Combinado (lado esquerdo da estrada, no sentido Combinado - Aurora do Tocantins) e um terceiro grande polje, com mais de 5 $\mathrm{km}$ em sua maior extensão interior, na porção centro-leste (coordenadas geográficas S $12^{\circ} 45^{\prime} 35^{\prime}$ ' e W 46 43' 19'), entre o córrego Tiúba e a Serra do Canabraval. Outras formas semelhantes foram constatadas a partir da análise de imagens de satélite disponíveis on-line (Google Earth). Contudo, ressalte-se sempre a necessidade de trabalhos de campo para detalhamento das informações levantadas via sensoriamento remoto, não sendo aqui, portanto citadas.

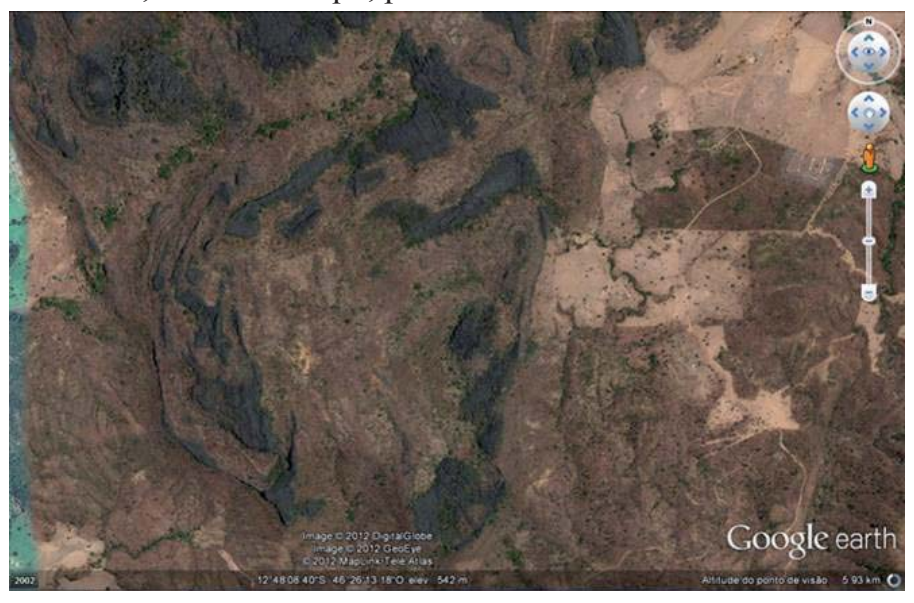

Figura 4 - Exemplo de Polje na área de estudo. (Fonte: GoogleEarth) 
Para o reconhecimento das dolinas, partiu-se da base teórica que as define como depressões cársticas de dimensões pequenas a intermediárias, podendo ter sua gênese ligada a fatores tanto climáticos quanto estruturais (FORD; WILLIAMS, 2007). Durante os trabalhos de campo, foi possível notar, por toda a área de estudo, a ocorrência de dolinas de dissolução e abatimento na sua grande maioria. Entretanto, puderam-se notar também algumas dolinas aluviais (alluvial streamsink doline), que segundo Jennings (1971), tendem a se formar em pontos onde o fluxo superficial migra, por sumidouros, para os vazios em rochas carbonáticas subjacentes. Pelo seu formato e coloração de suas águas, diversas lagoas situadas na porção noroeste da área (Figura 5) podem ter sua gênese associada ao alargamento de dolinas.

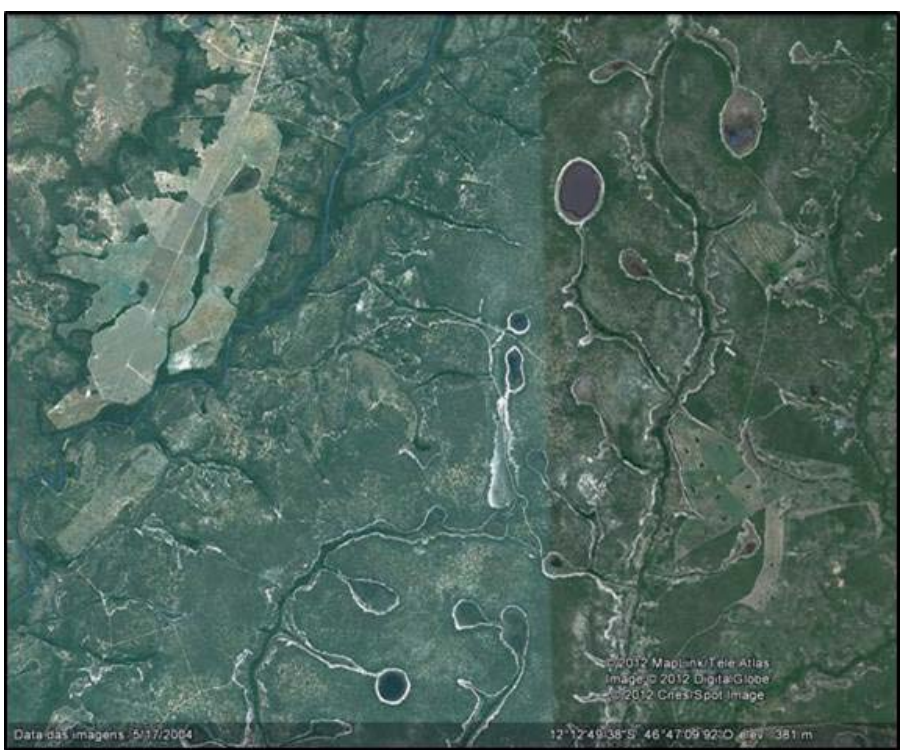

Figura 5 - Lagoas situadas na porção noroeste da área de estudo (Fonte: GoogleEarth, 2004).

$\mathrm{Na}$ área de estudo pode ser constatada a ocorrência de uma surgência de grande beleza cênica, rio Azuis (Figura 6). Essa feição não foi aqui tratada como uma ressurgência, pelo fato de não serem conhecidos, até o presente, os pontos e formas de recarga hídrica da mesma. Trabalhos de prospecção geofísica - eletrorresistividade - estão programados para serem realizados no âmbito de pesquisas de mestrado, que vêm sendo desenvolvidas no entorno do rio Azuis. Vale ressaltar que esta drenagem é tida pela população local, como o menor rio brasileiro, com $137 \mathrm{~m}$ de extensão.

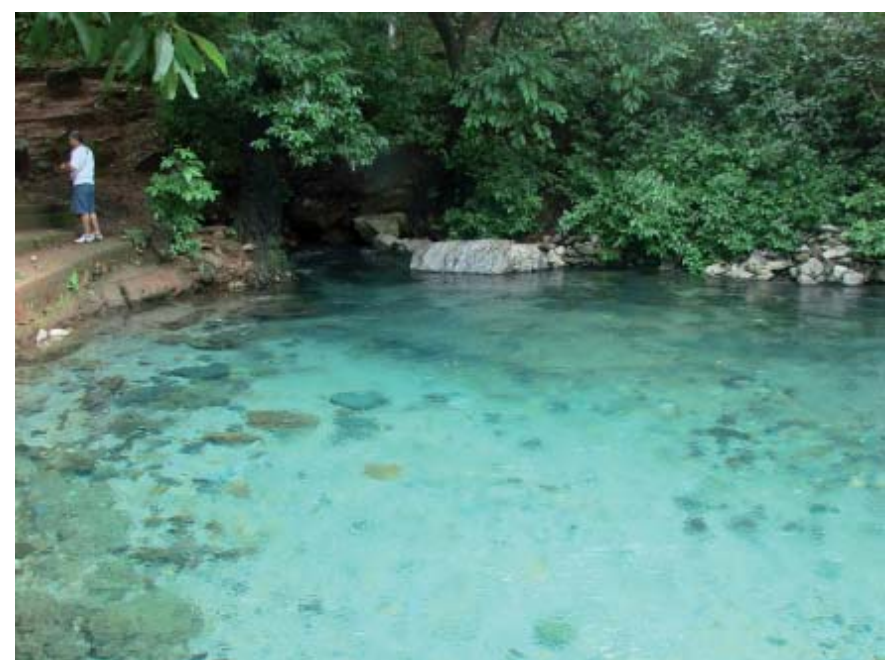

Figura 6 - Surgência cárstica, denominada rio Azuis.

\section{Endocarste}

No tocante ao endocarste, foram feitos levantamentos sobre a situação geográfica das cavernas existentes na área além de incursões exploratórias às principais cavidades para a descrição de suas feições espeleológicas, a fim de se caracterizar de maneira geral essas cavernas. Pode-se constatar que existem 128 cavernas cadastradas na Área Cárstica de Aurora do Tocantins, que é compreendida pelos paralelos $12^{\circ} 10^{\prime} 00^{\prime \prime} \mathrm{S}$ e $13^{\circ} 05^{\prime} 00^{\prime \prime} \mathrm{S}$ e os meridianos $46^{\circ} 10^{\prime} 00^{\prime} \mathrm{W}$ e $46^{\circ} 50^{\prime} 00^{\prime \prime} \mathrm{W}$. Desse total de cavidades, 83 apresentam dimensões reduzidas (inferiores a $50 \mathrm{~m}$ ), enquanto que apenas 3 cavernas possuem mais de $550 \mathrm{~m}$ de desenvolvimento (Figura 7). Quanto à declividade, pode-se notar que a maioria das cavernas se desenvolve em terrenos com média a baixa declividade (Figura 8), fator que contribui para um maior tempo de contato da água acidulada com a rocha carbonática, gerando vazios na mesma.

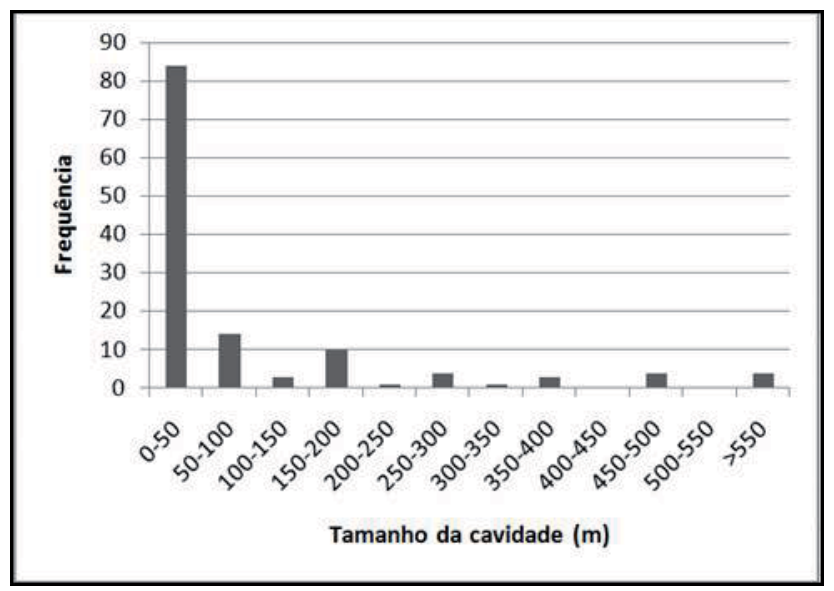

Figura 7 - Dimensões das cavernas na área cárstica de Aurora do Tocantins. 


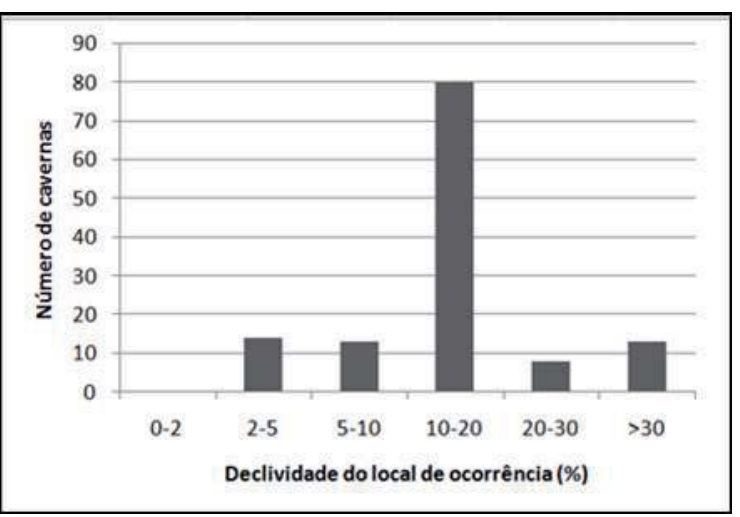

Figura 8-Declividades dos locais de ocorrência das cavernas.

Entre as maiores cavernas, destaca-se a Lapa do Bom Jesus, que possui grandes salões e passagens geologicamente condicionados pelo sistema de fraturas local. Situada à leste da cidade de Arraias, esta caverna possui uma grande variedade de espeleotemas de dimensões consideráveis, quando comparados aos demais encontrados por todo o estado do Tocantins. Outra cavidade que merece atenção é a Gruta dos Moura, que apresenta grande potencial paleontológico (OLIVEIRA et al., 2011), tendo sido realizadas várias escavações em seu interior. Essa caverna possui dois níveis (pavimentos), podendo seus estágios espeleogenéticos serem associados ao rebaixamento do nível de base local, rio Palma.

Em todas as cavernas foi constatada a presença de água, principalmente gotejamentos, indicando que as mesmas ainda estão em processo de evolução. As grutas da Cachoeira e da Guariroba apresentam água corrente (rio subterrâneo), enquanto a gruta das Rãs possui um pequeno lago em seu interior. Também nas proximidades dessa caverna pode ser notada a ocorrência de vários sumidouros no polje de Aurora do Tocantins, indicando sua conexão com o sistema de drenagem superficial.

Além dos espeleotemas comumente encontrados na maioria das cavernas, outros menos comuns também foram constatados como helictites, clavas e micro-travertinos com calcita cintilante. Em algumas cavernas foi constatada a presença de scallops, indicando comportamento turbulento do fluxo subterrâneo (TRAVASSOS, 2007). Tais feições estão sendo utilizadas para inferência de paleofluxos e correlação com o posicionamento dos atuais níveis de base locais.

\section{Uso e ocupação do solo}

O mapa de uso e ocupação mostra uma correlação com o mapa de relevo sombreado, apresentando os afloramentos carbonáticos situados na porção central da área, além de uma grande ocorrência na porção sudoeste (Figura 9). No mesmo mapa é possível notar que grande parte da área é destinada ao uso agrícola, com destaque para a porção leste, onde as plantações de soja nos platôs da Serra Geral dominam a paisagem.

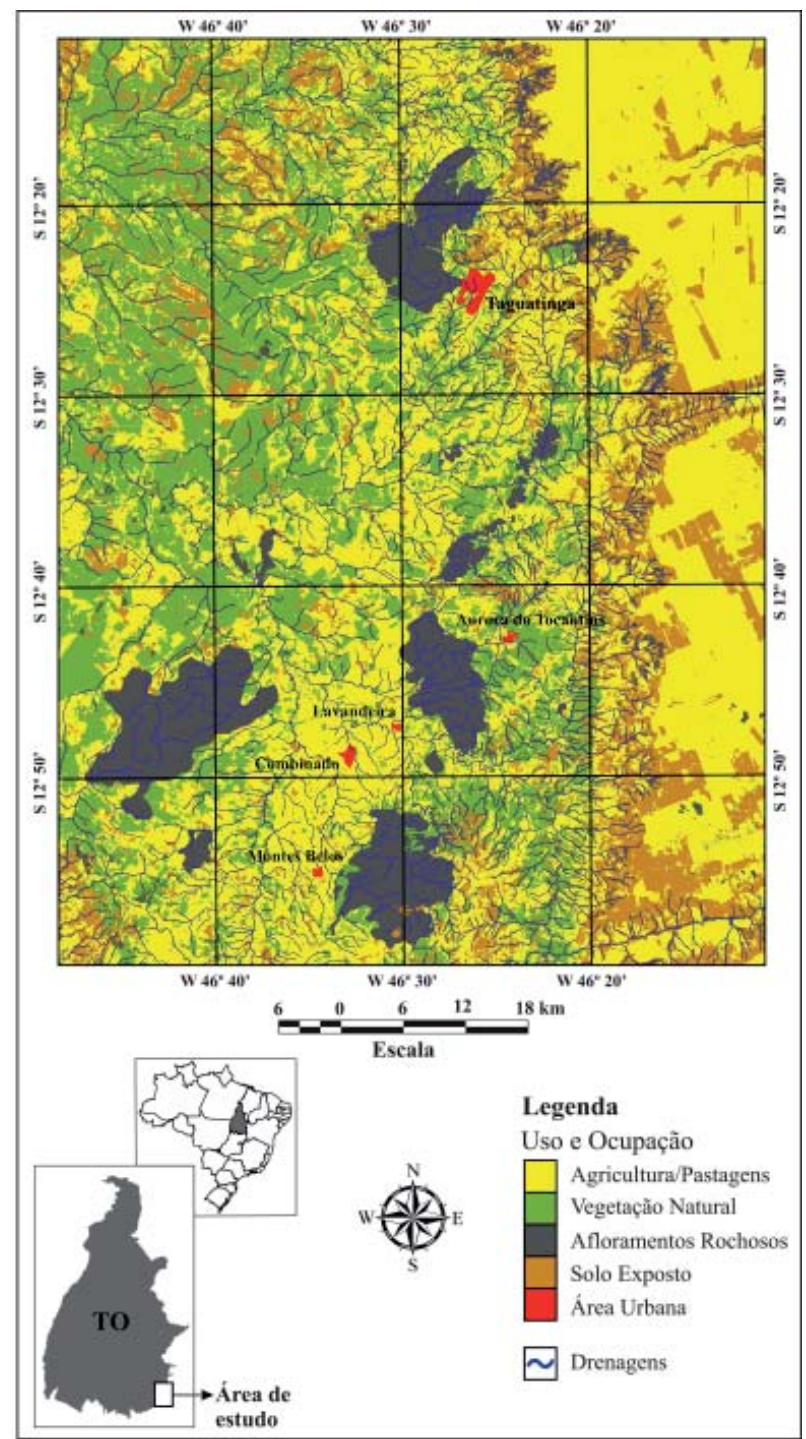

Figura 9 - Mapa de uso e ocupação do solo na área cárstica de Aurora do Tocantins.

Quanto à utilização das cavernas, a grande maioria não possui nenhum tipo de atividade desenvolvida em seu interior. Entretanto, vale ressaltar que algumas feições possuem grande valor histórico e cultural para a população local. A Lapa do Bom Jesus, por exemplo, é palco de grandes celebrações ecumênicas nos meses de agosto e setembro de cada ano, quando milhares de pessoas ali fazem e pagam promessas, como acontece no Santuário de Bom Jesus da Lapa - BA. Nos arredores da cidade de Aurora do Tocantins, várias cavernas (ex. Gruta das Rãs, Gruta do Sabiá) são frequentemente visitadas por turistas e moradores locais, mesmo não existindo um plano de manejo para a realização de tais atividades.

\section{Considerações finais}

Inserido num projeto que visa a caracterização física das cavernas da porção centro-sul do estado do Tocantins, o presente 
trabalho buscou fazer uma caracterização geral da área cárstica de Aurora do Tocantins, tendo em vista que esta porção do estado do Tocantins se apresenta como a principal área de ocorrência de cavernas em rochas carbonáticas do norte do Brasil.

Com o uso da metodologia clássica de estudos da geomorfologia cárstica (elaboração de mapas base, trabalhos de campo, e análise e discussão de dados em gabinete), foi possível fazer algumas considerações sobre os aspectos geomorfológicos da área estudada, a saber:

- Pode-se notar que a porção carbonática da área de estudo constitui uma superfície exumada a partir do recuo das vertentes areníticas da Serra Geral, e que recebem, portanto, contribuições hídricas alogênicas.

- A maioria das cavernas está situada em áreas com declividades pouco proeminentes, aumentando o tempo de contato da água acidulada com a rocha carbonática, e contribuindo para o desenvolvimento de feições mais concentradas na porção central da área de estudo.

- Algumas cavernas possuem grande potencial paleontológico e valor histórico cultural, como a Gruta dos Moura e Lapa do Bom Jesus, respectivamente.

- $\mathrm{O}$ rio Azuis constitui feição cárstica de elevado potencial turístico, devendo ser explorado com os devidos cuidados ambientais, tendo em vista que se apresenta como um local de alta fragilidade ambiental.

- A agricultura e as pastagens dominam a paisagem da área; principalmente na porção leste, onde pode-se notar a ocorrência de extensas lavouras de soja (Serra Geral).

Dado o grande número de cavidades e a pequena quantidade de mapas dessas feições, entende-se que a área apresenta diversas possibilidades para estudos tanto de cunho geológico quanto geomorfológico, dentre outros. Assim, entende-se que este estudo possa servir de base para outros trabalhos a serem desenvolvidos na região sudeste do estado do Tocantins. Recomenda-se ainda a elaboração de Plano de Manejo para as atividades turísticas ralizadas na área estudada, sobretudo, no entorno das cavernas e do rio Azuis.

\section{Agradecimentos}

O presente estudo foi desenvolvido com auxílio do Conselho Nacional de Desenvolvimento Científico e Tecnológico CNPq na forma de bolsa de produtividade em pesquisa, processo $\mathrm{n}^{\circ} 314759 / 2009-3$. O autor agradece à prefeitura de Aurora do Tocantins aos membros dos grupos de espeleologia Dolina e Tocantins Espelo Grupo pela ajuda nos trabalhos de campo.

\section{Referências bibliográficas}

AIRES DE CASAL, Manuel. Corografia brasílica ou Relação histórico-geográfica do Reino do Brasil. Belo Horizonte, Ed. Itatiaia; São Paulo, Ed. da Universidade de São Paulo, 1976.

BÖGLI, A. Karst hydrology and physical speleology. Berlin/New York: Springer, 1980.

BRASIL, Ministério das Minas e Energia. Secretaria Geral. Projeto RADAMBRASIL. Folha SD 23 Brasília; geologia, geomorfologia, pedologia, vegetação e uso potencial da terra. Rio de Janeiro, 1982, 660p.
CAMPOS, J. E. G.; DARDENE, M. A. A glaciação neopaleozóica na porção meridional da Bacia Sanfranciscana. Revista Brasileira de Geociências, 24(2), p. 65-76, 1997.

CAMPOS, J. E. G.; DARDENE, M. A. Estratigrafia e sedimentação da Bacia Sanfranciscana: Uma revisão. Revista Brasileira de Geociências, 27(3), p. 269-282, 1997.

CARVALHO JÚNIOR, O. A.; BERBET-BORN, M.; MARTINS, E. S.; GUIMARÃES, R. F.; GOMES, R. A. T.. Ambientes Cársticos In: FLORENZANO, Teresa Gallotti. Geomorfologia: conceitos e tecnologias atuais. São Paulo: Oficina de Textos, 2008.

DIAS, M. S.. Ficha de caracterização de cavidades. In: Congresso Brasileiro de Espeleologia, 27, Januária. Anais.., pp. 151-160, 2003.

FORD, D. C.; WILLIAMS, P. W.. Karst geomorphology and hidrogeology. United Kingdom: Wiley, 2007.

GARDNER, George. Viagem ao interior do Brasil, principalmente nas províncias do Norte e nos distritos do ouro e do diamante durante os anos de 1836-1841. Tradução Milton Amado. Belo Horizonte; Itatiaia; São Paulo: EDUSP, 1975.

JENNINGS, J.N. Karst. Cambridge: Mass \& London, 1971, 208p.

KARMANN, I.. Evolução e dinâmica atual do sistema cárstico do Alto vale do Rio Ribeira de Iguape, sudeste do Estado de São Paulo. São Paulo: Instituto de Geociências da Universidade de São Paulo, 1994. 228p. (Tese de Doutorado em Geoquímica e Geotectônica).

KARMANN, I.; SÁNCHEZ, L. E. Distribuição das rochas carbonáticas e Províncias espeleológicas do Brasil. Espeleo-Tema, 13, p. 105-167, 1979. OLIVEIRA, E. V.; NOVA, P. V. GOIN, F. J. e AVILLA, L. S. A new hyladelphine marsupial (Didelphimorphia, Didelphidae) from cave deposits of northern Brazil. Zootaxa, p. 1-12, 2011.

PALMER, A. N. Cave geology. Cave Books, 2007, 454 p.

PEREIRA, G. S. Expedição ao Jalapão. Revista Brasileira de Geografia, 5(4), p.573-620, 1943

PEREIRA, G.S. Expedição ao divisor de águas Tocantins-São Francisco. Revista Brasileira de Geografia, Rio de Janeiro, v. 4, n. 4: p. 85-130, 1942.

POHL, Joahann Emmanuel. Viagem no interior do Brasil. Trad. Milton Amado e Eugênio Amado. São Paulo: EDUSP, 1976.

ROSS, J. L. S. O registro cartográfico dos fatos Geomórficos e a questão da taxonomia do relevo. Revista do Departamento de Geografia FFLCH/USP, n. ${ }^{\circ}$ 6, 17-29, 1992.

SECRETARIA DO PLANEJAMENTO E MEIO AMBIENTE SEPLAN. Atlas do Tocantins: subsídios ao planejamento da gestão territorial. Diretoria de Zoneamento Ecológico-Econômico - DZE. 4 ed. Palmas, 2008,49p.

SGARBI, G. N. C. Arenitos eólicos da Formação Areado (Bacia Cretácea do São Francisco): Caracterização, diagênese e aspectos químicos. Revista Brasileira de Geociências, 21(4), p. 342-354, 1991.

SGARBI, G. N. C. The Cretaceous Sanfranciscan Basin, eastern plateau of Brazil. Revista Brasileira de Geociências, 30(3), p. 450-452, 2000. SOUZA, J. D.; KOSIN, M.; HEINECK, C. A.; LACERDA FILHO, J. V.; TEIXEIRA, L. R.; VALENTE, C. R.; GUIMARÃES, J. T.; BENTO, R. V.; BORGES, V. P.; SANTOS, R. A.; LEITE, C. A.; NEVES, J. P.; OLIVEIRA, I. W. B.; CARVALHO, L. M.; PEREIRA, L. H. M. ePAES, V. J. C.. Folha SD.23-Brasília. In: Schobbenhaus, C.; Gonçalves, J. H.; Santos, J. O. S.; Abram, M. B.; Leão Neto, R.; Matos, G. M. M.; Vidotti, R. M.; Ramos, M. A. B. e Jesus, J. D. A. (eds.). Carta geológica do Brasil ao milionésimo, Sistemas de Informações Geográficas - SIG, Programa Geologia do Brasil, CPRM, Brasília. CD-ROM, 2004.

TRAVASSOS, L. E. P.. Caracterização do carste da região de Cordisburgo, Minas Gerais. Dissertação (Mestrado) - Programa de Pós-graduação em Geografia - Tratamento da Informação Espacial. Pontifícia Universidade Católica de Minas Gerais. 2007, 98p.

VALERIANO, Márcio de Morisson. TOPODATA: Guia para Utilização de Dados Geomorfométricos Locais. 2008. Disponível em: $<$ http://www. dsr.inpe.br/topodata/data/guia_enx.pdf $>$. Acesso em: 17 out. 2010. 